\title{
openaccess
}

\section{Can Virtual Reality assist the recoupling of theory and practice in Civil Engineering education?}

\author{
Patricia Xavier ${ }^{1} \odot$ 0000-0002-5870-9659, Marc Holmes ${ }^{1} \oplus$ 0000-0002-8206-5451, Russell Evans ${ }^{2}$, \\ Jude Clancy ${ }^{1}$ @ 0000-0002-9138-3531 \\ ${ }^{1}$ Swansea University, Swansea, UK \\ ${ }^{2}$ Dawnus Construction, Swansea, UK \\ Corresponding author: p.a.xavier@swansea.ac.uk
}

Civil Engineering education is intended to prepare students for a career working in often large, dynamic and complex environments. Despite this, most education typically takes place in a classroom, with students engaging in learning conceptualised design processes while removed from engaging with authentic and contextualised tasks. Problem-based learning (PBL), where students are encouraged to take an inquiry-led rather than instructed approach to learning is often recommended as a solution to re-connecting theory and practice. Deriving the problem to be solved in PBL from real case studies from industry can add to authenticity. However, the scale and complexity of, for example, a working site, is difficult to replicate.

Virtual Reality (VR) can offer a realistic immersive experience and appears to have potential to effectively augment PBL in Civil Engineering education. This paper explores how familiar current students are with VR technology and how useful they perceive it to be for education. The paper also seeks to understand whether a relatively cheap and accessible VR solution (navigable site tour captured using $360^{\circ}$ photospheres, viewed using a Google Cardboard-type device and smartphone) can improve a PBL learning experience. Students were asked to complete a design exercise involving a large excavation. They were then invited to view a VR experience of an excavation of the same size in order for them to compare their conceptualised design with the experience of the actual investigation. Thematic analysis of student responses after the VR experience showed student responses were positive, with themes of fun, realism, improved sense of presence and scale emerging as perceived benefits. It is concluded that VR has good potential to improve PBL tasks in Civil Engineering education, however, it is identified that more research is required to understand whether VR in PBL can help to develop the spatial intelligence of classroom-taught students.

Keywords: Problem-Based Learning; Civil Engineering Education; Virtual Reality; Construction Management; Spatial Intelligence

Correspondence

Patricia Xavier (p.a.xavier@swansea.ac.uk)

doi: 10.1255/vrar2018.ch4

Citation: P. Xavier, M. Holmes, R. Evans and J. Clancy, "Can Virtual Reality assist the recoupling of theory and practice in Civil Engineering education?", in Proceedings of the Virtual and Augmented Reality to Enhance Learning and Teaching in Higher Education Conference 2018, Ed by J. Hudson and R. Kerton. IM Publications Open, Chichester, pp. 33-42 (2019). https://doi.org/10.1255/vrar2018.ch4

\section{c) 2019 The Authors}

This licence permits you to use, share, copy and redistribute the paper in any medium or any format provided that a full citation to the original paper is given.

Print ISBN: 978-1-906715-30-4 Online ISBN: 978-1-906715-28-1 


\section{Introduction}

Civil Engineering is concerned with both the artificial structures and natural systems that support a society: buildings, bridges, transport networks, river and coastal management, water and wastewater systems. The Institute of Civil Engineers (ICE, 2018) defines Civil Engineering as 'delivering social, economic and environmental value through infrastructure' (p. 6). A significant majority of Civil Engineering projects are of a large scale and complexity. In contrast, secondary and tertiary Civil Engineering education is predominantly classroom based, conducted in spaces that are several orders of magnitude smaller than the designs students may eventually work on during their professional career. As part of society, students (as we all do) constantly engage with the products of Civil Engineering: their own home; the road or rail they travel on; even the water they drink, and, the toilet they flush! However, it is clear that exposure to the products of Civil Engineering does little to convey the process of design and construction or reveal the role of the engineer to the user. Engineering is about the journey to the product, the identification of need, the ability to visualize and conceptualise a design and the translation of that design into reality, while managing safety, environmental risk, resources and budget.

In Civil Engineering education, students frequently engage in the front end of this design process, as required by the accrediting body in the UK, Institution of Civil Engineers (ICE). However, the experience is necessarily truncated, with the designs seldom leaving the paper or screen. This requires us to consider the impact on the learner of missing out on the final completion of the design process. What elements of learning are being left to only professional practice and what is the impact of this? Kolb's experiential learning cycle (Kolb, 1984) requires an experience to be active in order to be fully reflected upon and abstracted as learning. Arguably, Kolb's experiential learning cycle can never be fully completed in traditional Civil Engineering design as the spatial impact of a student's design, or the spatial complexity of a working site is not experienced. If students do not engage deeply with large-scale design, how does this affect their understanding of design? Planning of construction logistics requires site engineers to develop timing and movement strategies of large mechanical plant and stockpiles of materials well in advance. Structural designers have to visualise how changes in a design will impact on the function of a building or bridge. Much of building and infra- structure Civil Engineering activity is the management of the translation of conceptual or paper/screen-based plans to reality, for which spatial skills are vital.

There are competing bodies of research on characterization of spatial ability, including spatial intelligence (Gardner, 1983) and spatial orientation (Bodner \& Guay, 1997). In this paper, we adopt the definition of spatial intelligence as one of eight different intelligences, the others being linguistics, logical-mathematical, musical, bodily-kinesthetic, naturalistic, interpersonal and intrapersonal. Gardner's spatial intelligence is defined in (Davis, Christodoulou, \& Gardner, 2011) as "an ability to recognize and manipulate large-scale and fine-grained spatial images" (p. 6).

Studies have shown that with training, spatial intelligence can be improved (Feng, Spence, \& Pratt, 2014; Wright, Thompson, Ganis, Newcombe, \& Kosslyn, 2008). It therefore follows that a lack of physical design completion and spatial engagement in students' design means that spatial intelligence may not be developed in Civil Engineering students.

It is relevant to reflect that amongst employers there is general dissatisfaction in graduate outcomes. The most recent Institute of Engineering and Technology survey of employers revealed that only $62 \%$ of engineering employers believe that graduates have the right skills for a modern workplace (Institution of Engineering and Technology, 2017), although note that this is an increase from $48 \%$ in 2012. In addition, 54\% of businesses in the Built Environment sector report they see "recruiting engineering and technical staff with the right skills as a barrier to achieving their business objectives" (Institution of Engineering and Technology, 2017, p. 35). In an ICE survey asking employers 'Which abilities are the most important?' spatial skills was ranked fifth, cited by $34 \%$ of Civil Engineering employers (ICE, 2018).

Briefly considering the history of engineering in Higher Education can give context to the present difficulty that the sector appears to have in producing engineering graduates with satisfactory overall skill levels. Retrospective reviews of the history of engineering education in the U.K. (Forster, Pilcher, Tennant, Murray, Craig, \& Copping, 2017) and in the U.S. (Issapour \& Sheppard, 2015) reveal similar trends either side of the Atlantic, with tertiary education in the post-industrial era becoming increasingly theoretical and less practice based. This can be seen in the move away from the vocational 
tradition of the master craftsman and apprentice model of the late 1900 s to the split between vocational and academic engineering education in the 1950s, through to the initiatives to widen participation in higher education starting in the 1960s, and expanded in the UK from 1997 onwards. Increasing student numbers make regular hands-on, practical work more difficult to achieve.

A stronger focus on more theoretical, decontextualized content has also resulted from the Research Excellence Framework and the prioritization of research-active staff, which has had the consequence of de-emphasizing the requirement for teaching staff to have relevant practical expertise (Forster et al., 2017).

It is possible that as a vocational and deeply contextladen discipline, Civil Engineering may be disproportionately affected by these trends in comparison to other degree schemes (Barr, 2008; Tennant, Murray, Forster, \& Pilcher, 2015). The combined effects of research-active teaching and larger student numbers can be seen as leading to a prioritization over time of promoting the development of logical-mathematical intelligence over bodily-kinesthetic and spatial intelligence.

Problem-based learning (PBL) is often proposed as a solution to the re-coupling of theory and practice, and since the 1990s it has been implemented in Civil Engineering courses, predominantly through designbased modules. PBL is anchored in principles of experiential learning (Kolb, 1984) and constructive alignment (Biggs, 2003), requiring educators to set complex, reallife problems as the starting point for learning. Central aspects of PBL are that the problem to be solved is authentic (not theoretical), it is challenging, leads to open-ended outcomes and requires cooperative learning to support peer instruction. Through tackling a problem that is contextualized, with no single acceptable solution, students are required to discuss and judge for themselves the validity of relevant resources made available to them. Thus, students learn by constructing their own knowledge through the activities in which they participate. PBL closely aligns with the seven characteristics of good undergraduate teaching developed by Chickering and Gamson (1987), including the incorporation of active learning, frequent contact between staff and students and cooperation between students. Promoting PBL as an educational approach has been shown to develop leadership, communication, flexible thinking and respect in Engineering Education (Alves, Leão, Moreira, \& Teixeira, 2018).
However, the inherent limitations must be recognized. Given that many lecturing staff do not have practical experience in industry, and many have had a theoretically-based engineering education themselves, how possible is it to expect deeply contextualized problems to be routinely set?

Partnering with industry to set context-laden problems is one method of implementing the PBL approach. Industry can provide project data and background information with the pedagogic structure refined by the academic. There appears to be interest from industry in a collaborative approach to education. The recent IET skills survey reports interest amongst $27 \%$ of engineering firms to engage in further and higher education to develop courses that match the company's needs, with $11 \%$ seeking to expand their activities in this area (Institution of Engineering and Technology, 2017).

If the authenticity of PBL can be enhanced through industry collaboration, there still remains the inability to experience the end product of the exercise, which raises the question of whether students are fully engaging their spatial intelligence skills in Civil Engineering PBL.

Virtual Reality offers potential to overcome the resource and time hurdle of experiencing spatial design, and it has already been applied in Civil Engineering education Martin-Guiterrez, Navarro, \& Gonzalez (2011) tested the spatial ability of students, using tests for spatial relations (imagining rotations of objects) and spatial visualisation (ability to recognize 3D objects from their faces). The study required students in the test group to undertake training using augmented reality (AR) to visualize 2D to 3D projection. The study showed that compared to the control group, the engineering students engaging in the AR training improved their spatial ability test scores. Paes, Arantes, and Irizarry (2017) explored students' and professionals' perceptions of architectural space in immersive VR against non-immersive stereoscopic panoramic projection, and showed that the VR experience improved spatial perception within an architectural model. In this study, improved spatial perception is understood as improved interpretation of the spatial relations of the observed elements. Lucas (2018) explored how students' spatial perception of a timber frame building differed between the use of 2D images and when experienced in immersive VR. The immersive VR simulation led to better understanding of spatial qualities and improved understanding of structural components for $64 \%$ of students. 
This paper reports on a study using VR to test authenticity of an industry-supported PBL course. The research asks:

1. Do students understand the spatial extent of their designs?

2. Do navigable VR site tours have potential to enhance PBL?

3. Are $360^{\circ}$ photospheres and Google Cardboard suitable to deliver site tours for PBL?

\section{Methods}

\section{Participants}

Participants were recruited from a compulsory 10 credit Level 6 (final year of BEng degree) Construction Management module with 166 students enrolled. The module uses PBL with authentic learning material provided and assessed by both academics and industrial collaborators. The module content covers the logistics of the movement of plant, materials and people on a working site; scheduling and costing of construction activities, and, risk management.

\section{Pre-course questionnaire}

An online questionnaire was distributed at the start of the semester to all students enrolled on the module. Responses were requested and collated by a researcher not associated with the module. The aim of the questionnaire was to collect information on the previous site and work experience of the cohort. The participants were also asked about previous experience of $V R$, and how they proposed $V R$ could be used in teaching.

\section{Observations and interviews during VR session}

In the assignment selected for this case study, the students were learning about construction methodsthe process of comparing different construction options against time and cost. The problem scenario was set by Dawnus Construction, a locally based national contractor. The task was to install a $20 \mathrm{~m}$ long $\times 3 \mathrm{~m}$ diameter stormwater attenuation tank, with the invert $6 \mathrm{~m}$ below ground level. The students were set the task of finding the best options (safest, and ideally also quickest and cheapest) for excavation, installing the tank and back-filling.

The students worked in groups of four to six on the task over $2 \times 2$ hour sessions in consecutive weeks, using site plans and information about ground conditions. In the first session, they were required to produce outline costings and time estimates for two different method options. In the second session, they prepared a detailed method statement for their preferred method.

At the end of the second week and after submission of the task, students were invited to view navigable VR tours of the actual site on which the case study was based, both pre- and post-excavation, using smartphones and Google Cardboard headsets (see Figure 1).

The VR tours were recorded on two separate visits to the site using a Samsung Galaxy 360 (2017) camera, a tripod and a smartphone. The $360^{\circ}$ camera together with Google Cardboard combination is a comparatively cheap and accessible method of teaching with VR. The cost of a $360^{\circ}$ camera is typically $£ 200-£ 300(€ 220-€ 330)$ and a Google Cardboard headset costs $£ 5-£ 10$ (€5-€11). The photospheres were edited in Unity and the VR tours were created as downloaded apps on Google Play and the App store. During the study, students viewed the VR tour using a Google Cardboard headset and a smartphone. This allowed them to move between the preand post-excavation tours, and move to stand in many different locations inside and around the edge of the excavation, including some shots taken on the very edge of the excavation, allowing the viewer to experience a precipitous viewpoint.

In total, approximately 18 students chose to view the VR tour of the site, and five opted to be interviewed. The interviews lasted between 2:30 and 6:00 minutes. Of the five students who were interviewed, two were female,

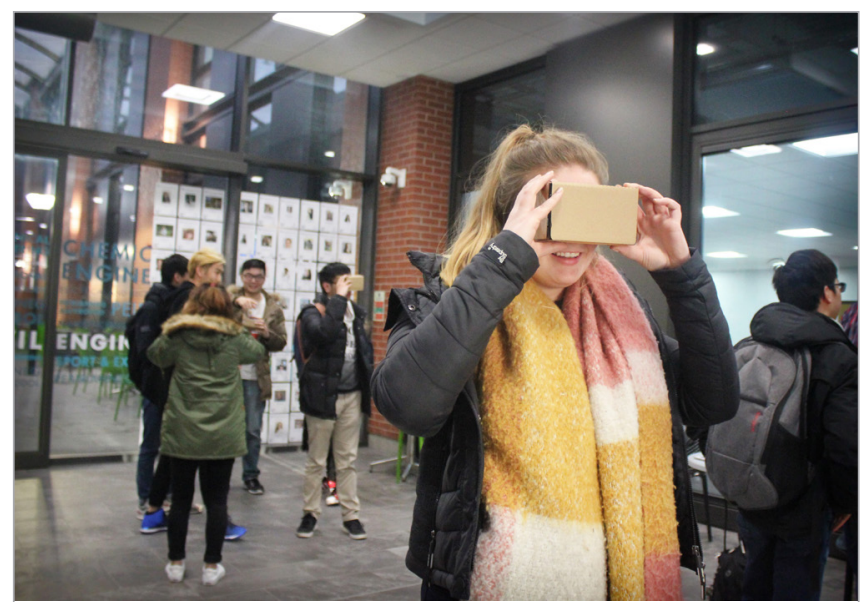

Figure 1. Student viewing the VR tour app using Google Cardboard and a smartphone. 
three were male. Three of the students were international and two were home/EU based.

This study underwent an ethical approval process. Informed consent was obtained from all participants prior to data collection. To mitigate potential bias in the responses, the interviews were conducted by an academic who was not involved in teaching or assessing this cohort of students. The students were informed that the module coordinator would not have access to the data until after the end of all module assessment.

\section{Data analysis}

Interviews were recorded and transcribed. Thematic analysis was carried out to analyze and interpret the student responses. The process of thematic analysis adopted follows the six-step recommendations of Braun and Clarke (2008). An inductive approach to response coding was chosen, in order to keep open the possibility of new information and themes emerging in addition to the original research questions posited. As a research method, the use of thematic analysis can never be fully objective as the researcher's own biases will inform interpretation. As part of a range of measures proposed to enhance the trustworthiness of thematic analysis, Nowell, Norris, White, \& Moules (2017) suggest the use of peer debriefing to mitigate bias. Therefore, a second researcher, unconnected with the use of VR or teaching on the module, was invited to review the coding and interpretation of thematic analysis at multiple stages.

\section{Results \\ Quantitative data}

Students were questioned about their previous experiences of $V R$ and previous site experience. The questionnaires were completed online, prior to the VR tour session. There were 40 respondents out of a cohort size of 166 , a response rate of $24 \%$. The percentage of female respondents was 30\%, male $70 \%$.

Figure 2 indicates that just over half of the students (55\%) have had some construction related work experience, with $35 \%$ having had a medium-term placement (typical of a summer placement).

Figure 3 shows that most students have had experience of VR, with only $11 \%$ of respondents saying they have not had any experience. The Google Cardboard headset (or equivalent) is the most frequently mentioned system. Systems mentioned in the "Other" category were Playstation Gaming and Samsung Gear VR.

Students were invited to explain how they had previously used VR in free text questions, distinct categories were derived inductively, and these are presented in Figure 4. Gaming came out as the most common use of

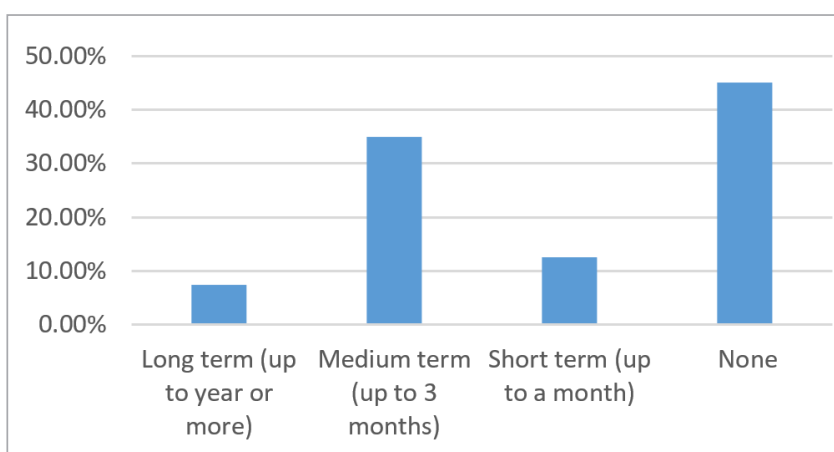

Figure 2. Proportion of students with work experience in the construction sector.
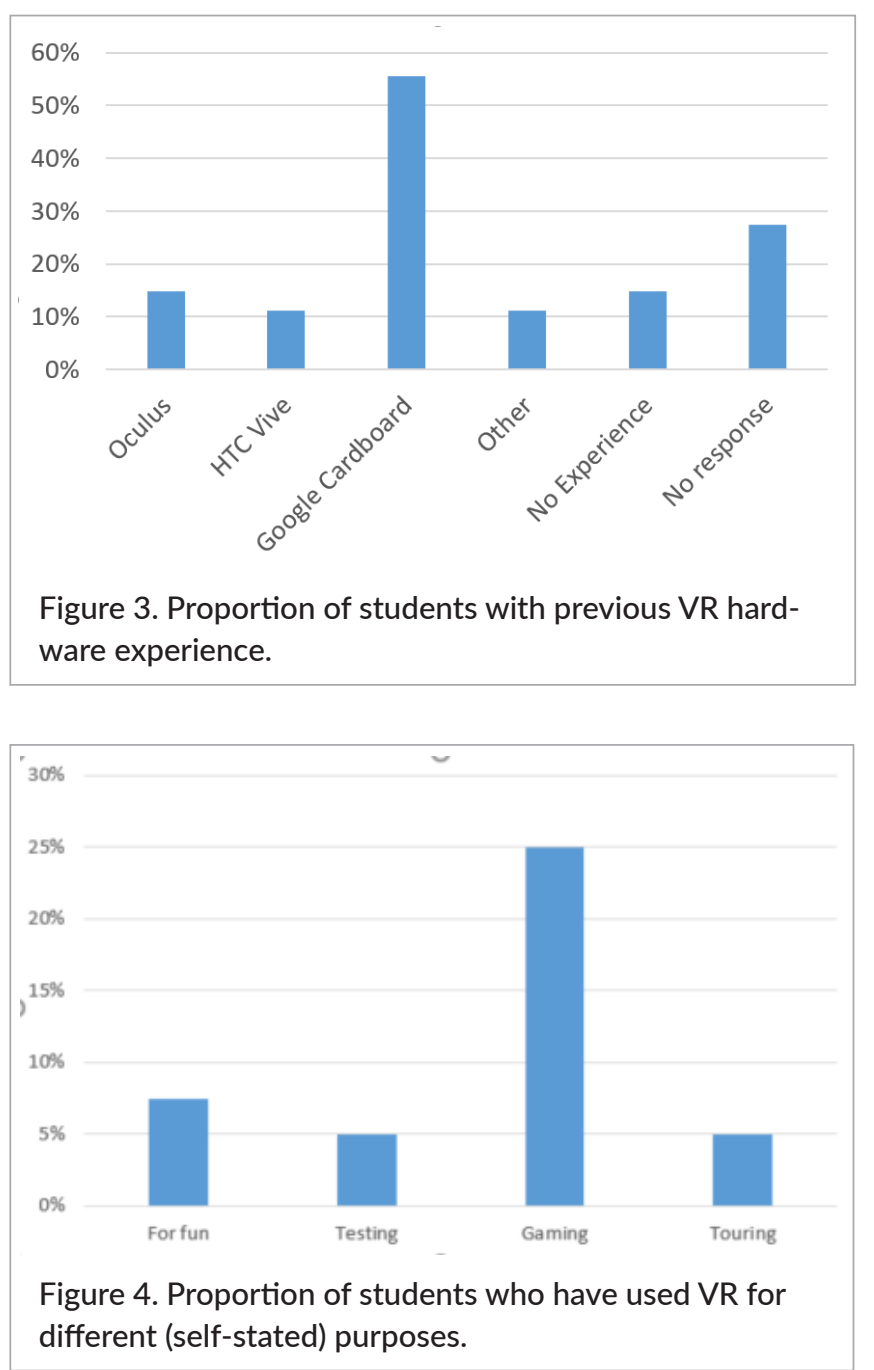
VR (25\%), with other students mentioning they used it for fun $(7.5 \%)$, to test or explore VR as a system $(5 \%)$ or for touring (5\%).

\section{Qualitative Data 1-Pre-course questionnaire}

A free text question in the pre-course questionnaire asked "Can you propose any ways that Virtual Reality could be used in teaching construction management?". Out of 21 responses to the question, two students stated they had no idea how VR could aid the module, and one student stated it would be "Not really useful". Many students picked up on the potential for site visits, for instance: "Virtual site visit experience". Some went further, specifically referencing it as a safer way to perform high risk site visits, for example: "Visualise installations in high risk environments (seaward face of a pier subject to rough waters, elevated areas subject to rough weather, etc.)", and, "It can provide life experience in a new way in 100\% safety". Some saw benefit in being able to 'time travel' on a site, to see progress more quickly: "showing a sped-up timeline of a build", and "Being able to wander through construction sites at different stages of construction". Linked to this, one student mentioned having control of seeing stages of construction: "Perhaps augmented reality would be beneficial for construction phases, to be able to peel back the layers of a building and see what materials are used". One student appeared to want to make the unseen seen: "giving a real idea of how forces really act on buildings".

The examples above are relatively passive, with the students viewing and exploring a scene or information. Other students (predominantly those who had experience in VR gaming) proposed more active use of $V R$ as a tool to manage construction. Optioneering emerged as a theme, the ability to rapidly prototype, for example, "To simulate different scenarios in the workplace", and "Demonstrating potential/proposed construction", or to communicate a potential design more clearly: "To introduce the new idea with VR. For example, showing the construction plan before make, how it looks like, and how it going to be built. The idea would be more clearly than using the paper or on-screen. It can show like in first person." One student appeared to express the notion/belief that it could offer experiential feedback on designs, helping to inform more creative design:

So we can see what we're designing; sometimes the terminology creates a barrier and we then only design what we are supposed to design systematically whilst we can have a look at what we're designing gives us a better understanding and maybe allows us to see things differently and maybe perhaps get a bit creative.

\section{Qualitative Data 2-Interviews following VR experience}

The observations of the students who were using the VR system were not formally recorded, however, it was noted that the 18 students who tried the VR tour appeared to be surprised or enjoyed the experience.

The interviewers asked the students questions about the task and the VR experience, seeking to understand if it has any potential to add value to the project-based learning exercise.

Do students understand the scale of their designs? The students were asked "How does the excavation align with your predictions?", intending to elicit whether the scale experienced conformed with the scale predicted. Results from the interviews were inconclusive, with only one student stating surprise at the scale, "once I visualise it now... you don't feel how deep it is... it's bigger than I thought it would be". It is not clear whether the other students were surprised at the scale or not, as it became apparent that the students had interpreted the question in a different way to that intended. While it was anticipated that students would comment on the size of the excavation, some instead chose to compare the design of the excavation instead (most had designed the excavation edges at a $1: 1$ slope to maintain soil stability, while in the real site, $1.5 \mathrm{~m} 1.5 \mathrm{~m}$ stepped sides were used. This can be seen in the comment "Fairly similar, but they've used different supports for the walls, it is quite different". As the interviewee speaks only of the design and not the scale, it cannot be determined whether the scale was different to what was anticipated. One respondent appeared to reference scale in saying, "I think it cannot show the level of the hole, how the depth is. Because we cannot take the photo as the cross section", indicating skepticism of how useful the experience was for scale reliability.

Do navigable VR tours have the potential to enhance PBL?

All respondents enjoyed the opportunity to view the VR tours, seen in responses to the question "Did you enjoy the experience?" such as: "Yeah, it was really good fun", and "Yes, it was really good". It is not clear whether the enjoyment was due to the novelty of $V R$ or the usefulness, one 
student referred to the novelty factor as appealing: "it's quite new, it's got that gimmick to it". Experience of $V R$ is becoming more mainstream, two thirds of the respondents to the survey had experienced some form of $V R$, however despite students being familiar with VR, the system was still welcomed, for example, the same student said, "Yeah yeah yeah, I've had experience before, something similar in a design environment to walk through a building".

When asked why the experience was enjoyable, there were again consistencies in the responses, including the theme of difference, for instance, "It was just a bit different", with one student drawing a direct comparison between the classroom exercise and the VR tour: "It gives you a different perspective of what you are looking at, it's not just on a drawing". Themes of realism and presence also emerged, for example, "it... put you in a real life situation more like it would actually be on site", and, "... it's realistic". There was also a comment on how it aided rapid visual understanding of the site, "it's shortened the time you need to visualise the whole entire experience".

When asked the question "How does the VR experience affect your understanding of the task?", all respondents were again positive, with a theme of clarity emerging, "I think it clarifies the task a lot more"; "I can understand the site connection clearly"; and "the VR experience somehow gives you a better idea". The realism theme also emerged again, for instance, "it sort of puts you in more of a real life situation", and "I guess it gives me that realism element". One student also expressed how much easier it is to experience the VR site than to interpret the drawings in the traditional manner in which they had been engaged, for example, "you don't have to imagine what it's like". Some drew direct comparisons between site visits and the VR experience "I can know the site... clearly without going down to the site", and "Normally when you go on site, you gain ideas and experiences, and the VR experience somehow gives you a better idea".

When asked the question, "Would you have liked to have earlier access to the scenario to do the first task and why?", all students answered positively, for instance, "Yes, sure, sure", "Yes", "It can be helpful", "I think it would a little". Clarity again emerged as a theme "I think I can know the site clearly", and "I think it would have given me more insight". The realism theme also came up again, "... some sites you can go to Google maps, but that's not quite the same thing as when you can turn around and be there". One student also referred to site health and safety, "Because we would know the site clearly and find some place or location that would be dangerous for our job, so we can deal with it first before the job".

\section{Are $360^{\circ}$ photospheres and Google Cardboard} suitable to deliver site tours for PBL?

In response the question "Would you have changed the app?", the results were mixed, with one student apparently content, for instance, "No, I thought it was really good, it worked as well as I expected, it was easy to use". Two of the students mentioned the button sensitivity, "Maybe the buttons on the cover are not very sensitive"; "It's quite hard to click the buttons to change location". The same student also wanted more information to be imparted, "It would be nice to have a map to know where you are in relation to the site". The image quality was also criticised, "It would be better to be better pixelated".

In response to the question 'do you have any other comments?' there were requests for additional features, for instance, "see specific information in different views about soils"; "if we click the button, if there are some text showing what it is, how is the depth or the condition, it will be very more comprehensive".

\section{Discussion}

The case study described here adds to the growing number of studies exploring the value that VR could add to Civil Engineering Education (Lucas, 2018; MartinGuiterrez et al., 2011; Paes et al., 2017). Civil Engineering is concerned with large scale structures, and the research questions were designed to explore student perceptions of how VR could be used in a Construction Management module. The student cohort is reasonably VR-literate, with only $11 \%$ of the respondents to the pre-course questionnaire saying that they have never experienced VR. The most commonly accessed form of VR was a GoogleCardboard/smartphone system (55\%) and the most common use of VR was for gaming (25\%). Most students had experienced work on site (55\%).

\section{Do students understand the scale of their designs?}

The withholding of the VR tours until after the assessment was completed was intended to test whether the students, who had been set a highly spatial task centered entirely on the comparison of dimensions, were able to appropriately translate the distances 
they were reading on paper into an understanding of the spatial extent of the design, and the experience of being inside or beside it. If they were, then the experience of being in the VR tour would not be a surprise in terms of scale, and vice versa. Consider that the excavation required was $6 \mathrm{~m}$ deep. An average height person standing within the excavation would be surrounded by earth walls extending more than $4 \mathrm{~m}$ above their heads. There would be no line of visibility to the rest of the site at the deepest extent. There are health and safety risks associated with entering and exiting, communication between workers inside and outside, and from workers and machinery falling into the excavation from the edge. It was of interest to know whether these factors had been considered by the students.

Only one student expressed surprise at the scale, "I realise it's much bigger than what I anticipated it to be". However, the questioning was flawed, as many students interpreted the question as asking about the shape of the excavation, rather than the size. The interviewers had been deliberately asked not to mention scale to the interviewees, however on reflection it would have been useful to ask the specific question and probe further whether their experience of the size of the excavation conformed to their expectations, as the questioning was not sufficient to derive this.

Since at least one student reported surprise at the scale, it is intended to repeat this exercise to investigate further. Rather than allowing the students to view the VR tours, and then formally interview them about their experience, it is intended to video the interview with the students while they are experiencing the tour, to capture their initial physical and verbal reactions, following the "think aloud" protocol (Eccles \& Arsal, 2017). Interviewees will be asked specifically about how the scale of the excavation compares to their prediction.

\section{Do navigable VR site tours have potential to enhance PBL?}

The research question relates to the difficulty of setting context-full site engineering PBL tasks in a classroom setting, and whether augmenting classroom tasks with VR has the potential to improve authenticity. The online questionnaire asked students to propose uses for VR, and the post-VR questionnaire was designed to probe how the experience of $V R$ added to their understanding of the task.
Previous experience in VR appeared to have an influence on how students proposed to use VR in the module. With one exception, those with previous VR gaming experience had consistently high expectations of interactivity, citing possible uses as, for example "to simulate different scenarios", while those who had previously experienced VR tours or only briefly experimented with the technology, more usually cited passive uses of VR, for instance, navigating a site tour. This may have implications, as if VR becomes a more widely used technology and less of a novelty, students may expect more active use of VR (e.g., designing and interacting with their own systems) than passive uses (e.g., the VR tour used in this study).

The class exercise preceding the VR tour was designed to be an exemplar PBL exercise, with authenticity derived from close industrial partnership to set the task, high levels of contact between faculty and staff during the work sessions, an open-ended problem and in-built complexity. Despite meeting the requirements of PBL, this study has shown that there are limitations when PBL is applied to a spatial design problem, which were revealed once the students had viewed the VR tours. All students expressed enjoyment of the VR tours, for example, "Yeah, it was really good fun". The tours contributed a sense of realism "more of a real life situation" and presence, "you can turn around and be there", and, their understanding of the task was rapidly clarified, "it's shortened the time you need to visualise the whole entire experience". The data suggests that the use of VR in PBL for large-scale engineering tasks could be both an enjoyable and effective additional resource.

\section{Are $360^{\circ}$ photospheres and Google Cardboard suitable to deliver site tours for PBL?}

This research question was intended to test the suitability of the combination of $360^{\circ}$ photospheres and Google Cardboard for use in PBL. There are many ways to access $V R$, including full headset and manual control (e.g., Oculus, HTC Vive). $360^{\circ}$ photospheres and Google Cardboard were deliberately chosen as a cheaper and more accessible system for deployment to large student numbers. The VR tours can run as an app with most students' smartphones. The questions asked were intended to probe student satisfaction with this physical VR option, and look for possible improvements. 
In the online survey, $55 \%$ of students had already experienced Google Cardboard technology or similar, with far fewer students having experienced more advanced integrated headsets, HTC Vive (10\%) and Oculus (15\%).

In the post-VR tour interviews, two students reported satisfaction with the system and two students reported that the button sensitivity needed to be improved. There were also comments asking for more information to be embedded, for example, "see specific information in different views about soils" and a map to determine location, "It would be nice to have a map to know where you are in relation to the site".

The combination of $360^{\circ}$ photospheres and Google Cardboard/smartphone was selected over a more interactive system, such as HTC Vive, for reasons of practicality. Due to cost, this would be the only feasible solution were this to be used for the full cohort size of 166. It was of interest to know whether the VR experience of this cheaper and simpler VR hardware (with fewer opportunities for quality interaction and poorer visual resolution) was appealing and perceived as useful by the students. Taking the comments about the users' experience of the hardware together with the positive comments about the VR tour experience, the data suggest that the smartphone headset is a suitable combination for use in PBL, if features including embedding information and improving navigation are added. It is however, significant that the students in this study had limited experience of more interactive systems. Should fully immersive VR systems become more mainstream, it is possible that the Google Cardboard/smartphone combination may be perceived as a lower quality and less desirable solution.

\section{VR as an aid to re-coupling theory and practice in Civil Engineering education?}

Forster et al. (2017) in their polemic review of UK Construction education echoed the concerns voiced in the US by Issapour and Sheppard (2015) in saying that trends of research intensiveness and the policy of widening access in higher education has led to a decoupling of theory from practice in engineering education. Taking the current higher education model as a baseline for modification, increased work experience and increased involvement from industry have been proposed as potential solutions to recouple theory and practice and produce graduate engineers who are more ready for modern industry. While real site experience clearly offers a richer and more valid learning experience than VR currently can, there are significant practical and health and safety constraints restricting the number of students that can have regular and meaningful access to a site. There are also temporal restrictions in what can be seen at any one time. In a traditional higher education setting, PBL can offer elements of real-world complexity, particularly when the resources are sourced from industry, as in this study. However, given the highly spatial nature of many aspects of Civil Engineering, this study indicates that even industry-led PBL is limited by the fact that, inevitably, scaled-down exercises are carried out, with students not experiencing the spatial extent of their designs, therefore potentially not being provided with adequate visual feedback needed to develop their spatial intelligence. This could have implications for consideration of health and safety-if the excavation was understood to be smaller, fewer or less robust, precautions may be anticipated to be needed.

This study has also shown that the use of the relatively cheap Google Cardboard/smartphone hardware VR experience has potential to usefully augment industryled PBL, offering students increased enjoyment, sense of realism and presence and better contextual understanding of the task.

\section{References}

Alves, A.C., Leão, C.P., Moreira, F., \& Teixeira, S. (2018). Project-based learning and its effects on freshmen social skills in an engineering program. In Human Capital and Competences in Project Management. https://doi.org/10.5772/intechopen.72054

Barr, B. (2008). UK Civil Engineering in the twentyfirst centuary. Proceedings of the Institution of Civil Engineers - Management, Procurement and Law, 161, 17-23.

Biggs, J.B. (2003). Teaching for quality learning at University. Buckingham: Open University Press/ Society for Research into Higher Education.

Bodner, G.M., \& Guay, R.B. (1997). The Purdue Visualization of Rotations Test. The Chemical Educator, 2(4), 1-17. https://doi.org/10.1007/ s00897970138a

Braun, V., \& Clarke, V. (2008). Using thematic analysis in psychology. Qualitative Research in Psychology, 3, 77-101. 
Chickering, A.W., \& Gamson, Z.F. (1987, March). Seven principles for good practice in undergraduate education. AAHE Bulletin, 3-7.

Davis, K., Christodoulou, J., \& Gardner, H. (2011). The theory of multiple intelligences. In S. \& S.B. Kaufman (Ed.), Cambridge Handbook of Intelligence (pp. 485503). Cambridge: Cambridge University Press. Retrieved from https://howardgardner01.files. wordpress.com/2012/06/443-davis-christodoulouseider-mi-article.pdf

Eccles, D.W., \& Arsal, G. (2017). The think aloud method: What is it and how do I use it? Qualitative Research in Sport, Exercise and Health, 9(4), 514-531.

Feng, J., Spence, I., \& Pratt, J. (2014). Playing an action video game reduces gender differences in spatial cognition. Psychological Science, 18(10), 850-855.

Forster, A.M., Pilcher, N., Tennant, S., Murray, M., Craig, N., \& Copping, A. (2017). The fall and rise of experiential construction and engineering education: Decoupling and recoupling practice and theory. Higher Education Pedagogies, 2(1), 79-100. https:// doi.org/10.1080/23752696.2017.1338530

Gardner, H. (1983). Frames of mind: The theory of multiple intelligences. New York: Basic Books.

ICE. (2018). ICE PROFESSIONAL SKILLS A Report by the Skills Review Group. Retrieved from https://www. ice.org.uk/ICEDevelopmentWebPortal/media/ Documents/News/ICE News/ICE-Skills-report-2018. pdf

Institution of Engineering and Technology. (2017). Skills \& demand in industry. IET 2017 Survey, (211014), 4. Retrieved from http://www.theiet.org/factfiles/education/skills2013-page.cfm

Issapour, M., \& Sheppard, K. (2015). Evolution of American engineering education. Conference for Industry and Education Collaboration ASEE.
Retrieved from http://www.indiana.edu/ ciec/ Proceedings_2015/ETD/ETD315_IssapourSheppard. pdf

Kolb, D.A. (1984). Experiential learning: Experience as the source of learning and development. Englewood Cliffs, NJ: Prentice-Hall.

Lucas, J. (2018). Immersive VR in the construction classroom to increase student understanding of sequence, assembly, and space of wood frame construction. Journal of Information Technology in Construction, 23(November 2017), 179-194.

Martin-Guiterrez, M.A., Jorge, Navarro, R.E., \& Gonzalez, M.A. (2011). Mixed reality for development of spatial skills of first-year engineering students. In Frontiers in Education Conference, T2D-1T2D-6.

Nowell, L.S., Norris, J.M., White, D.E., \& Moules, N.J. (2017). Thematic analysis: Striving to meet the trustworthiness criteria. International Journal of Qualitative Methods, 16, 1-13.

Paes, D., Arantes, E., \& Irizarry, J. (2017). Immersive environment for improving the understanding of architectural 3D models: Comparing user spatial perception between immersive and traditional virtual reality systems. Automation in Construction, 84, 292303. https://doi.org/10.1016/j.autcon.2017.09.016

Tennant, S., Murray, M., Forster, A., \& Pilcher, N. (2015). Hunt the shadow not the substance: The rise of the career academic in construction education. Teaching in Higher Education, 20(7), 723-737. https://doi.org/1 0.1080/13562517.2015.1070342

Wright, R., Thompson, W.L., Ganis, G., Newcombe, N.S., \& Kosslyn, S.M. (2008). Training generalized spatial skills. Psychonomic Bulletin and Review, 15(4), 763771. https://doi.org/10.3758/PBR.15.4.763 